\title{
Age associated axonal features in HNPP with 17p11.2 deletion in Japan
}

\section{H Koike, M Hirayama, M Yamamoto, H Ito, N Hattori, F Umehara, K Arimura, S Ikeda, Y Ando, M Nakazato, R Kaji, K Hayasaka, M Nakagawa, S Sakoda, K Matsumura, O Onodera, M Baba, H Yasuda, T Saito, J Kira, K Nakashima, N Oka, G Sobue}

J Neurol Neurosurg Psychiatry 2005;76:1 109-1114. doi: 10.1136/jnnp.2004.048140
See end of article for authors' affiliations

Correspondence to: Dr Gen Sobue, Department of 'Neurology, Nagoya University Graduate School of Medicine, Nagoya 4668550, Japan; sobueg@ med.nagoya-u.ac.jp

Received 20 June 2004 Revised version received 28 September 2004 Accepted

18 November 2004
Objective: To clarify age related changes in the clinicopathological features of hereditary neuropathy with liability to pressure palsy (HNPP) in Japanese patients with deletion of $17 \mathrm{p} 11.2$, particularly concerning axonal abnormalities.

Methods: Forty eight proband patients from 48 HNPP families were assessed as to clinical, electrophysiological, and histopathological features, including age associated changes beyond those in controls.

Results: Motor conduction studies showed age associated deterioration of compound muscle action potentials in nerves vulnerable to repetitive compression (median, ulnar, and peroneal nerves), but not in others such as the tibial nerve. Sensory conduction studies revealed more profound reduction of action potentials than motor studies with little age related change. Large myelinated fibre loss was seen in the sural nerve irrespective of age at examination.

Conclusions: Irreversible axonal damage may occur at entrapment sites in motor nerves in HNPP patients, progressing with aging. Sensory nerves may show more profound axonal abnormality, but without age association. The electrophysiological features of HNPP are presumed to be a mixture of abnormalities occurring from early in life and acquired features caused by repetitive insults at entrapment sites. Unlike Charcot-Marie-Tooth disease type 1A, age associated axonal damage may not occur unless the nerves are subjected to compression.
$\mathrm{H}$ ereditary neuropathy with liability to pressure palsy (HNPP) is an autosomal dominant disorder characterised by recurrent transient nerve palsies associated with compression at the typical anatomic sites of potential nerve entrapment. ${ }^{12}$ Tomacula, which represent focal thickening of the myelin sheath, characteristically are seen in both sensory and motor nerves in HNPP. ${ }^{3-6}$ This disorder usually is associated with a $1.5 \mathrm{Mb}$ deletion of locus $17 \mathrm{pl} 1.2$, which contains the gene for peripheral myelin protein 22 (PMP22). ${ }^{7-9}$ HNPP therefore appears to represent a reciprocal product of Charcot-Marie-Tooth disease type lA (CMTIA), which is associated with duplication of PMP22. ${ }^{10} \mathrm{PMP} 22$ is an important factor for regulation of Schwann cell proliferation and apotosis. ${ }^{11}$ As the Schwann cell plays an important role in maintenance of the axon, axonal loss associated with demyelination has been reported to occur in patients with CMTIA. ${ }^{12-15}$ Age associated reduction of compound muscle action potential (CMAP) amplitude resulting from large-axon loss has been reported in $\mathrm{CMTlA}^{15}$ and is closely related to clinical manifestations and functional impairment. ${ }^{14}$

In Western countries, the clinical and electrophysiological features of HNPP have been described on a large scale. ${ }^{16-20}$ Characteristic electrophysiological findings are multifocal slowing of conduction at sites of entrapment, prolonged distal latency (DL), mild slowing of motor nerve conduction velocity (MCV), and diffuse abnormality of sensory nerve conduction velocity (SCV). ${ }^{16-20}$ However, there have been no similar large scale investigations of the clinical and electrophysiological features of HNPP in Asian subjects. Furthermore, it has not been clarified whether electrophysiological and histopathological abnormalities, particularly axonal features, worsen with aging in HNPP as happens in CMTIA.
The present investigation was carried out in Japan and we studied HNPP including its electrophysiological and histopathological features, especially in relation to aging.

\section{METHODS}

\section{Patients and DNA diagnosis}

An HNPP survey was conducted by the study group for hereditary neuropathy in Japan under the auspices of the Ministry of Health, Labor, and Welfare. ${ }^{1521}$ A total of 48 proband patients from 48 HNPP families, whose $17 \mathrm{p} 11.2$ deletion was confirmed, were investigated. The mean age (SD) of the patients at examination was 41.8 (18.5) years (table 1). All subjects underwent clinical examination by at least one neurologist. Patients with chronic alcoholism or vitamin deficiency were not included. Four patients manifested mild glucose intolerance. To confirm the diagnosis of HNPP, DNA analyses for the presence of a chromosome 17p11.2-12 deletion, which includes a $1.5 \mathrm{Mb}$ region containing the PMP22 gene between CMT1A-REP repeats, were performed in all patients. For most patients these analyses were performed at the Department of Neurology at Nagoya University Graduate School of Medicine as described previously, ${ }^{22}$ while DNA was analysed at other institutions for the rest. The characteristic deletion in HNPP was detected by Southern analysis, probing with PMP22 CDNA, and CMTIAREP fragments as described previously. ${ }^{22-24}$ Hybridisation with PMP22 cDNA and pNEAl02, pHK1.0P, and pHK5.2 probes, which map within the CMTIA-REP, was carried out

\footnotetext{
Abbreviations: CMAP, compound muscle action potential; CMT1A, Charcot-Marie-Tooth disease type 1A; DL, distal latency; HNPP, hereditary neuropathy with liability to pressure palsy; MCV, motor nerve conduction velocity; PMP22, peripheral myelin protein 22; SCV, sensory nerve conduction velocity; SNAP, sensory nerve action potential
} 
to determine the gene dose of the $1.5 \mathrm{Mb}$ region containing PMP22. Deletion of one copy of the PMP22 gene, compared to the presence of two copies in normal controls, was genetically identified as HNPP. Informed consent was obtained in all patients, and the study as a whole was approved by the Ethics Committee of Nagoya University Graduate School of Medicine.

\section{Electrophysiological study}

Motor and sensory conduction was measured in the median, ulnar, tibial, peroneal, and sural nerves, using a standard method with surface electrodes for stimulation and recording. ${ }^{25}{ }^{26}$ Motor conduction was investigated in the median, ulnar, tibial, and peroneal nerves, recording from the abductor pollicis brevis, abductor digiti minimi, abductor hallucis brevis, and extensor digitorum brevis muscles, respectively. The following nerve segments were used for calculating MCV: wrist to elbow for the median nerve, wrist to distally at the elbow for the ulnar nerve, ankle to popliteal fossa for the tibial nerve, and ankle to distally at the fibular head for the peroneal nerve. Sensory conduction was investigated in the median, ulnar, and sural nerves, using antidromic recording from ring electrodes at the second and fifth digit for the median and ulnar nerves respectively, and bar electrodes at the ankle for the sural nerve. SCV was calculated for the distal segment. Amplitudes of CMAP and sensory nerve action potential (SNAP) were measured from the baseline to the first negative peak. Waveforms also were analysed to assess temporal dispersion. For motor nerves, we measured duration from the onset to the first crossing of the baseline in the CMAP. ${ }^{27}$ For sensory nerves, duration from the onset of the SNAP to the first negative peak rather than to the first crossing of the baseline was measured to avoid artefacts from overlapping muscle action potentials. ${ }^{25}$ This was necessary because some motor axons have thresholds similar to those of large myelinated sensory axons, resulting in superimposition on the SNAP that modifies the waveform, especially when abnormal nerves are examined. ${ }^{28}{ }^{29}$ Because of a delay at the neuromuscular junction, the initial phase of the waveform of SNAP is less likely to be affected by muscle action potentials than the later phase. ${ }^{29}$

Control values were obtained in 171 normal volunteers (51.0 (SD 16.3) years of age; male:female, 89:82) for the median nerve, 170 (51.2 (SD 16.4) years of age; male:female,

Table 1 Characteristics of 48 Japanese HNPP probands with deletion of 17p1 1.2-12

\begin{tabular}{ll}
\hline Clinical features & $\mathbf{n}(\%)$ \\
\hline Age at onset, years & 33.1 (SD 19.3) \\
Age at examination, years & $41.8($ SD 18.5) \\
Men/women & $38 / 10$ \\
Family history & $24(50 \%)$ \\
Athletic impairment during childhood & $1(2 \%)$ \\
Pes cavus or hammer toe & $2(4 \%)$ \\
Atrophy in the legs & $6(13 \%)$ \\
Pattern of neuropathy & $41(85 \%)$ \\
Multiple mononeuropathy & $7(15 \%)$ \\
Symmetric polyneuropathy & $11(23 \%)$ \\
History of transient nerve palsy & $18(38 \%)$ \\
Median nerve & $7(15 \%)$ \\
Ulnar nerve & $29(60 \%)$ \\
Radial nerve & $10(21 \%)$ \\
Peroneal nerve & \\
Brachial plexus & $46(96 \%)$ \\
Activity of daily living & $2(4 \%)$ \\
Able to walk & 0 \\
Unable to walk &
\end{tabular}

Age at onset, age at first awareness of neuropathic symptoms; Family history, obvious family history of recurrent transient nerve palsies.
88:82) for the ulnar nerve, 161 (51.8 (SD 16.6) years of age; male:female, 85:76) for the tibial nerve, 171 (54.2 (SD 16.7) years of age; male:female, 92:79) for the peroneal nerve, and 163 (52.2 (SD 16.7) years of age; male:female, 85:78) for the sural nerve.

\section{Histopathological study}

Sural nerve biopsy was performed in 14 patients as described previously. ${ }^{30}{ }^{31}$ Informed consent was obtained beforehand. Specimens were divided into two portions. The first portion was fixed in $2.5 \%$ glutaraldehyde in $0.125 \mathrm{M}$ cacodylate buffer ( $\mathrm{pH}$ 7.4) and embedded in epoxy resin for morphometric study. The density of myelinated fibres was assessed in toluidine blue stained semithin sections using a computer assisted image analyser (Luzex FS; Nikon, Tokyo, Japan) to calculate the densities of small and large myelinated fibres as described previously. ${ }^{32-34}$ A fraction of the glutaraldehyde fixed sample was processed for a teased fibre study, in which at least 100 single fibres were isolated; their pathologic condition was assessed microscopically according to criteria described previously. ${ }^{32}{ }^{35}$ The second portion of the specimen was fixed in $10 \%$ formalin solution and embedded in paraffin. Sections were cut by routine methods and stained with haematoxylin and eosin as well as by the Klüver-Barrera and Masson trichrome methods. Control values were obtained from 13 autopsy cases in which patients died of non-neurologic diseases (48.5 (SD 23.5) years of age; male:female, $7: 6$ ). Specimens were processed in the same manner as for HNPP patients.

\section{Statistical analysis}

Quantitative data are presented as the mean (SD) and were compared with control values using the Mann-Whitney U test. To determine the relationship of electrophysiological and histopathological indices and age at examination, Pearson's correlation coefficient analysis was carried out. To determine whether worsening of these indices in HNPP patients with aging was significantly greater than in normal controls, regression slopes of patient and control groups were compared. Values of $\mathrm{p}$ less than 0.05 were considered to indicate significance.

\section{RESULTS}

\section{Clinical features}

The age at first awareness of neuropathic symptoms in the 48 probands was 33.1 (SD 19.3) years (table 1). The male:female ratio was 38:10. An obvious family history of recurrent transient nerve palsies was present for 24 patients (50\%). Only one patient $(2 \%)$ reported athletic impairment during childhood. Deformity in the distal part of the lower limbs such as hammer toe or pes cavus was present in two patients $(4 \%)$. Atrophy was noted in the leg in six patients (13\%). The pattern of neuropathic symptoms was multiple mononeuropathy associated with recurrent transient nerve palsies in 41 patients $(85 \%)$, while the other seven (15\%) manifested mainly a symmetric polyneuropathy pattern. A history of transient nerve palsy was noted in the median, ulnar, radial, and peroneal nerves in $11(23 \%), 18(38 \%)$, seven $(15 \%)$, and $29(60 \%)$ patients, respectively. Signs of brachial plexus palsy were reported in $10(21 \%)$. With respect to the activities of daily living, all patients were non-disabled or only mildly disabled, except for two $(4 \%)$ who became unable to walk.

\section{Electrophysiological features}

Motor conduction studies showed variable degrees of abnormality in individual nerves (table 2). For the median nerve, MCV was significantly slowed compared to normal controls $(p<0.0001)$. This slowing of MCV was present regardless of age at examination, and there was no 
significant difference in regression slopes in the correlation between MCV and age at examination (regression slope -0.073 for HNPP $v-0.064$ for controls). DL was very prolonged (179\% of controls) and prolongation tended to worsen as age at examination increased $(r=0.47)$. The CMAP was reduced to various degrees in most patients and showed further reduction with advancing age $(\mathrm{r}=-0.67$; fig 1). Worsening of both DL and CMAP with age was significantly more prominent than in controls, as evident from comparison of regression slopes $(\mathrm{p}<0.0001$ and $<0.01$, respectively).

For the ulnar nerve, mild to moderate slowing of MCV and prolongation of DL were noted regardless of age at examination, while CMAP decreased with advancing age $(\mathrm{r}=-0.65)$. CMAP diminution with aging was significantly worse in patients than in controls (regression slope -0.109 for HNPP $v$ -0.021 for controls; $p<0.0001$ ). For the tibial nerve, slowing of MCV and prolongation of DL also were mild to moderate in most patients of all ages. Reduction of CMAP was also present in all ages examined but, in contrast to other nerves, the relationship of reduction to aging was indistinguishable from that in controls (regression slope -0.062 for HNPP $v$ -0.069 for controls). For the peroneal nerve, the age associated decrement in CMAP was significantly greater than in controls $(p<0.05)$. Slowing of MCV and prolongation of DL were present in patients of all ages, but no significant worsening with aging was seen in comparison with controls.

As for sensory conduction studies, slowing of conduction velocity was present as in motor nerves. SCV of the median nerve tended to slow with increasing age at examination
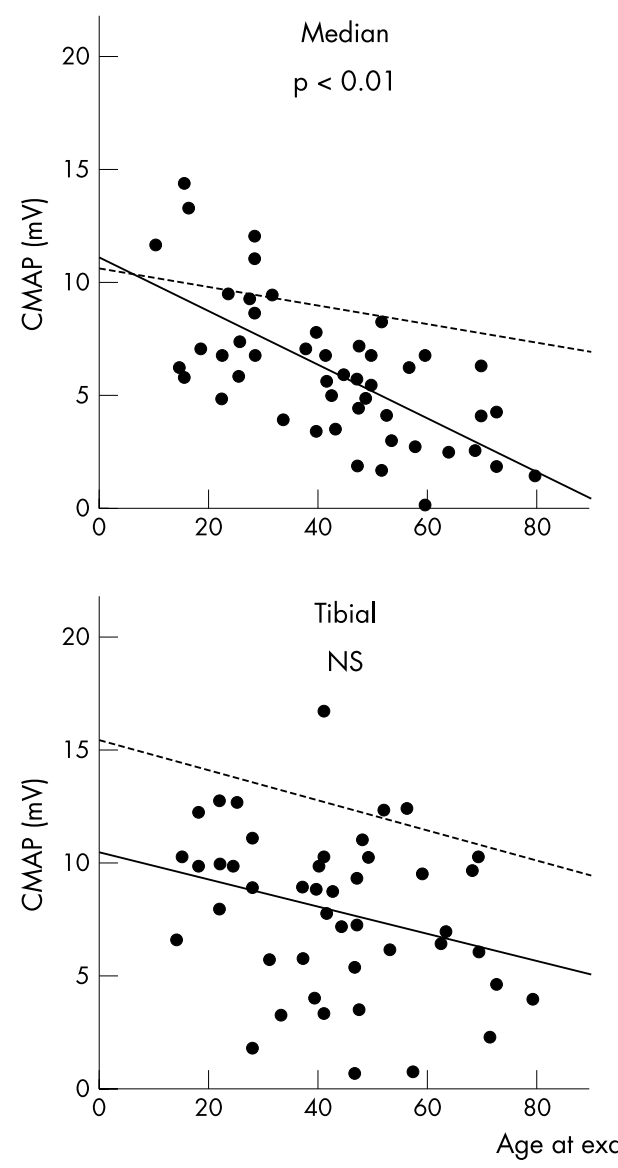

Figure 1 Correlation between CMAP and age at examination in HNPP patients and normal controls. Filled circles represent indices in HNPP patients, bold lines represent regression lines for HNPP patients, and broken lines represent regression lines for normal controls. Comparing regression slopes of normal controls and HNPP patients, CMAP of the median, ulnar, and peroneal nerves, but not the tibial nerve, in HNPP patients were significantly more reduced with increasing age at examination. $(\mathrm{r}=-0.41)$. This age associated worsening was significantly greater than in controls $(\mathrm{p}<0.05)$, while SCV of the ulnar and sural nerves did not show a correlation with age. Reduction of SNAP was conspicuous in the median $(24 \%$ of control amplitude), ulnar (28\%), and sural $(42 \%)$ nerves. Age associated reduction of SNAP was seen in the median $(\mathrm{r}=-0.50)$, ulnar $(\mathrm{r}=-0.45)$, and sural $(\mathrm{r}=-0.37)$ nerves, but the rate of change was not worse than in controls.

Duration of CMAP and SNAP was prolonged in all nerves examined compared to normal controls, suggesting the presence of temporal dispersion. ${ }^{27}$ Compared to controls, significant age associated worsening was seen only in the SNAP of the median nerve $(\mathrm{p}<0.0001)$.

\section{Histopathological features} nerves was mildly, but not significantly, reduced compared to normal controls (7738 (SD 1253) v 8561 (SD 1289) fibers/ $\mathrm{mm}^{2}$; table 3 ). The density of large myelinated fibres was significantly reduced from that in controls (2458 (SD 730) $v$ 3258 (SD 736) fibers $/ \mathrm{mm}^{2} ; \mathrm{p}<0.01$ ) but that of small myelinated fibres was not (5280 (SD 1025) v 5302 (SD 655) fibers $/ \mathrm{mm}^{2}$ ). Axonal sprouting was not conspicuous in any case. Although the density of large myelinated fibres decreased as age at examination increased $(r=-0.70)$, the rate of reduction was indistinguishable from that in controls (regression slope -27.1 for HNPP $v-26.0$ for controls) because large myelinated fibres were reduced even at younger ages. Teased fibre preparations revealed frequent tomacular change $(41.5 \%$ (SD $15.8 \%)$ ). The frequency of segmental
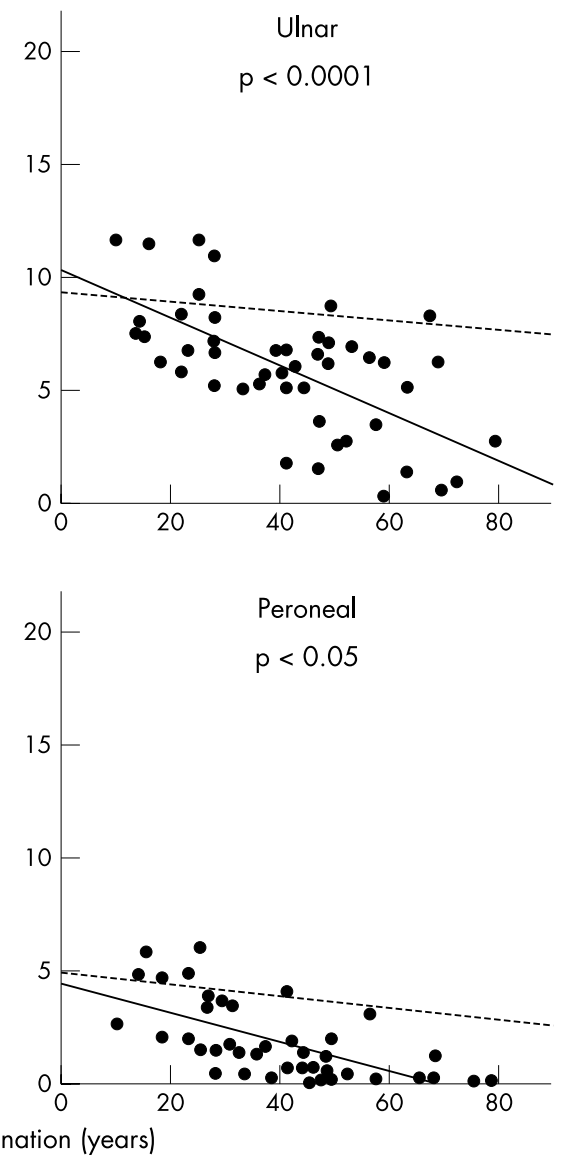

Average total myelinated fibre density in patients' sural 
Table 2 Nerve conduction studies

\begin{tabular}{|c|c|c|c|c|c|c|c|c|c|c|}
\hline & \multicolumn{7}{|c|}{ HNPP } & \multicolumn{3}{|l|}{ Controls } \\
\hline & \multicolumn{4}{|c|}{ Nerve conduction measures } & \multicolumn{3}{|c|}{ Correlation to aging } & \multirow[b]{2}{*}{ Mean (SD) } & \multicolumn{2}{|c|}{ Correlation to aging } \\
\hline & $\mathbf{n}$ & Mean (SD) & $\begin{array}{l}\% \text { of } \\
\text { controls }\end{array}$ & $\begin{array}{l}\text { p Values for } \\
\text { controls* }\end{array}$ & $r \dagger$ & $\begin{array}{l}\text { Regression } \\
\text { slope }\end{array}$ & $\begin{array}{l}\text { p Values for } \\
\text { controls } \ddagger\end{array}$ & & $r \dagger$ & $\begin{array}{l}\text { Regression } \\
\text { slope }\end{array}$ \\
\hline \multicolumn{11}{|l|}{ Motor conduction } \\
\hline \multicolumn{11}{|l|}{ Median nerve } \\
\hline$M C V(\mathrm{~m} / \mathrm{s})$ & 47 & $46.0(5.3)$ & 80 & $<0.0001$ & -0.25 & -0.073 & NS & $57.6(3.8)$ & -0.27 & -0.064 \\
\hline $\mathrm{DL}(\mathrm{ms})$ & 47 & 6.1 (1.8) & 179 & $<0.0001$ & 0.47 & 0.046 & $<0.0001$ & $3.4(0.4)$ & 0.19 & 0.005 \\
\hline CMAP (mV) & 48 & 6.3 (3.2) & 77 & $<0.0001$ & -0.67 & -0.122 & $<0.01$ & $8.2(2.9)$ & -0.24 & -0.042 \\
\hline Duration (ms) & 32 & $5.4(0.8)$ & 115 & $<0.001$ & 0.13 & 0.006 & NS & $4.7(0.9)$ & -0.07 & -0.004 \\
\hline \multicolumn{11}{|l|}{ Ulnar nerve } \\
\hline$M C V(\mathrm{~m} / \mathrm{s})$ & 47 & $46.9(8.3)$ & 81 & $<0.0001$ & 0.04 & 0.018 & NS & $58.0(4.6)$ & -0.22 & -0.062 \\
\hline $\mathrm{DL}(\mathrm{ms})$ & 47 & $3.8(0.8)$ & 146 & $<0.0001$ & 0.17 & 0.009 & NS & $2.6(0.3)$ & 0.06 & 0.001 \\
\hline CMAP (mV) & 48 & $6.0(3.0)$ & 81 & $<0.001$ & -0.65 & -0.109 & $<0.0001$ & $7.4(1.8)$ & -0.20 & -0.021 \\
\hline Duration (ms) & 28 & $5.9(1.2)$ & 116 & $<0.0001$ & -0.22 & -0.016 & NS & $5.1(0.7)$ & -0.01 & -0.001 \\
\hline \multicolumn{11}{|l|}{ Tibial nerve } \\
\hline$M C V(\mathrm{~m} / \mathrm{s})$ & 45 & $39.6(4.5)$ & 86 & $<0.0001$ & -0.02 & -0.006 & NS & $46.0(3.8)$ & -0.34 & -0.079 \\
\hline $\mathrm{DL}(\mathrm{ms})$ & 45 & $5.5(1.3)$ & 138 & $<0.0001$ & 0.15 & 0.011 & NS & $4.0(0.6)$ & 0.11 & 0.004 \\
\hline CMAPs (mV) & 45 & $7.9(3.7)$ & 67 & $<0.0001$ & -0.29 & -0.062 & NS & $11.8(3.5)$ & -0.33 & -0.069 \\
\hline Duration (ms) & 25 & 5.7 (1.3) & 114 & $<0.01$ & -0.18 & -0.012 & NS & $5.0(0.7)$ & -0.17 & -0.008 \\
\hline \multicolumn{11}{|l|}{ Peroneal nerve } \\
\hline$M C V(\mathrm{~m} / \mathrm{s})$ & 38 & $35.7(5.7)$ & 76 & $<0.0001$ & -0.11 & -0.042 & NS & $47.4(4.5)$ & -0.38 & -0.101 \\
\hline $\mathrm{DL}(\mathrm{ms})$ & 38 & 7.7 (2.3) & 167 & $<0.0001$ & -0.002 & -0.00004 & NS & $4.6(1.1)$ & 0.04 & 0.002 \\
\hline CMAP (mV) & 41 & $1.9(1.8)$ & 56 & $<0.0001$ & -0.65 & -0.067 & $<0.05$ & $3.4(2.0)$ & -0.22 & -0.027 \\
\hline Duration (ms) & 16 & $6.4(0.9)$ & 131 & $<0.0001$ & -0.09 & -0.006 & NS & $4.9(0.9)$ & -0.17 & -0.009 \\
\hline \multicolumn{11}{|l|}{ Sensory conduction } \\
\hline \multicolumn{11}{|l|}{ Median nerve } \\
\hline $\mathrm{SCV}(\mathrm{m} / \mathrm{s})$ & 42 & $38.6(10.1)$ & 69 & $<0.0001$ & -0.41 & -0.235 & $<0.05$ & $56.3(5.3)$ & -0.26 & -0.085 \\
\hline SNAP $(\mu \mathrm{V})$ & 48 & $6.8(6.2)$ & 24 & $<0.0001$ & -0.50 & -0.178 & NS & $28.0(11.5)$ & -0.45 & -0.327 \\
\hline Duration (ms) & 26 & $0.9(0.4)$ & 150 & $<0.0001$ & 0.56 & 0.011 & $<0.0001$ & $0.6(0.1)$ & -0.11 & -0.001 \\
\hline \multicolumn{11}{|l|}{ Ulnar nerve } \\
\hline $\mathrm{SCV}(\mathrm{m} / \mathrm{s})$ & 41 & $36.8(8.4)$ & 68 & $<0.0001$ & -0.13 & -0.069 & NS & $54.5(5.5)$ & -0.28 & -0.093 \\
\hline $\operatorname{SNAP}(\mu \mathrm{V})$ & 48 & $6.6(6.4)$ & 28 & $<0.0001$ & -0.45 & -0.170 & NS & $23.8(10.3)$ & -0.37 & -0.240 \\
\hline Duration $(\mathrm{ms})$ & 26 & $0.9(0.2)$ & 150 & $<0.0001$ & 0.08 & 0.001 & NS & $0.6(0.1)$ & -0.05 & -0.00004 \\
\hline \multicolumn{11}{|l|}{ Sural nerve } \\
\hline $\mathrm{SCV}(\mathrm{m} / \mathrm{s})$ & 43 & $36.4(6.9)$ & 74 & $<0.0001$ & -0.13 & -0.052 & NS & $49.2(4.8)$ & -0.12 & -0.035 \\
\hline $\operatorname{SNAP}(\mu \mathrm{V})$ & 48 & $7.1(5.9)$ & 42 & $<0.0001$ & -0.37 & -0.124 & NS & $16.8(7.8)$ & -0.38 & -0.177 \\
\hline Duration (ms) & 21 & $0.9(0.3)$ & 129 & $<0.05$ & 0.23 & 0.004 & NS & $0.7(0.1)$ & 0.21 & 0.002 \\
\hline
\end{tabular}

*Mann-Whitney U test; †Pearson's correlation coefficient; tregression slopes of HNPP and controls were compared.

Control values were obtained in 171 normal volunteers for the median nerve, 170 for the ulnar nerve, 161 for the tibial nerve, 171 for the peroneal nerve, and 163 for the sural nerve.

CMAP, compound muscle action potential; DL, distal latency; Duration, duration from the onset to the first crossing of the baseline in the CMAP and duration from the onset of the SNAP to the first negative peak; MCV, motor nerve conduction velocity; NS, not significant; SCV, sensory nerve conduction velocity; SNAP, sensory nerve action potential.

de/re-myelination also was significantly high $(25.6 \%$ (SD $13.9 \%), \quad \mathrm{p}<0.001)$. Axonal degeneration was slightly increased $(3.6 \%(\mathrm{SD} 3.8 \%))$ and was seen even in young patients in contrast to controls.

\section{DISCUSSION}

This study demonstrated clinical, electrophysiological, and histopathological features of Japanese HNPP patients with the $17 \mathrm{p} 11.2$ deletion. Although recurrent transient nerve palsies are the characteristic feature of this disease, a minority of patients showed a symmetric polyneuropathy pattern, as previously reported. ${ }^{16-18} 36$ Electrophysiological features of slowing of conduction velocities and varying degrees of abnormality among individual nerves, agreed well with previous reports of Western populations. ${ }^{16-20}$ Slowing of MCV in our series seemed more marked than in previous reports. ${ }^{16-18} 20$ The fact that we only examined probands of HNPP families and did not include affected siblings could

Table 3 Histopathological study of the sural nerve

\begin{tabular}{|c|c|c|c|c|c|c|c|c|}
\hline & \multicolumn{5}{|l|}{ HNPP $(n=14)$} & \multicolumn{3}{|c|}{ Controls $(n=13)$} \\
\hline & \multirow[b]{2}{*}{ Mean (SD) } & \multirow[b]{2}{*}{$\begin{array}{l}\text { p Values for } \\
\text { controls* }\end{array}$} & \multicolumn{3}{|c|}{ Correlation to aging } & \multirow[b]{2}{*}{ Mean (SD) } & \multicolumn{2}{|c|}{ Correlation to aging } \\
\hline & & & $r \dagger$ & $\begin{array}{l}\text { Regression } \\
\text { slope }\end{array}$ & $\begin{array}{l}\text { p Values for } \\
\text { controls } \neq\end{array}$ & & $r \dagger$ & $\begin{array}{l}\text { Regression } \\
\text { slope }\end{array}$ \\
\hline \multicolumn{9}{|l|}{ Myelinated fibre density (no. $/ \mathrm{mm}^{2}$ ) } \\
\hline Total & 7738 (1253) & NS & -0.45 & -29.6 & NS & 8561 (1289) & -0.73 & -39.9 \\
\hline Large & $2458(730)$ & $<0.01$ & -0.70 & -27.1 & NS & $3258(736)$ & -0.83 & -26.0 \\
\hline Small & $5280(1025)$ & NS & -0.05 & -2.5 & NS & $5302(655)$ & -0.50 & -13.9 \\
\hline \multicolumn{9}{|l|}{ Teased fibre study (\%) } \\
\hline Tomacular change & $41.5(15.8)$ & - & -0.21 & -0.18 & - & - & - & - \\
\hline Segmental de/re-myelination & $25.6(13.9)$ & $<0.001$ & 0.39 & 0.30 & NS & $6.9(6.5)$ & 0.82 & 0.22 \\
\hline Axonal degeneration & $3.6(3.8)$ & NS & -0.35 & -0.07 & $<0.05$ & $1.6(1.8)$ & 0.81 & 0.06 \\
\hline
\end{tabular}

*Mann-Whitney U test; †Pearson's correlation coefficient; łregression slopes of HNPP and controls were compared.

NS, not significant. 
account for the difference, or greater slowing might be characteristic of Japanese patients. In the peroneal nerve, it seems that the amplitude of CMAP is lower and the distribution of DL is wider than in Western populations even in normal controls. ${ }^{26}$ Japanese people usually sit on the floor at home, rather than on chairs, and sometimes sit with their legs folded underneath them. This traditional Japanese sitting position may induce peroneal nerve injury.

A striking finding in our study was a reduction in CMAP with increasing age at examination. This feature was observed in the median, ulnar, and peroneal nerves but not in the tibial nerve. The median nerve passes through the carpal tunnel, predisposing it to entrapment injury, while the ulnar and peroneal nerves are vulnerable to repetitive compression injury at the cubital tunnel and fibular head, respectively, as suggested by the high frequency of episodic palsy of these nerves compared with the tibial nerve. Repetitive movement and nerve stretching at these sites also may contribute to injury. Thus, individual nerve-specific CMAP reduction with increasing age probably resulted from the cumulative effects of repetitive damage; conduction slowing caused by demyelination would be prominent at entrapment sites, as previously reported..$^{16-18}{ }^{20}$ In the present study, demyelination also showed progression over time as demonstrated by age associated prolongation of DL and SCV in the median nerve for conduction through the entrapment site. However, in the ulnar and peroneal nerves, where electrophysiological indices were recorded distally from sites vulnerable to compression, no age associated worsening of MCV, SCV, or DL was observed, suggesting that myelin abnormality distal to the entrapment site does not worsen with advancing age. Thus, CMAP reduction in the median, ulnar, and peroneal nerves would reflect secondary axonal involvement complicating demyelination at the entrapment site. This age associated axonal involvement in a primarily demyelinating condition is similar to that observed in CMTIA with PMP22 duplication. ${ }^{12} 14$ 15 However, unlike CMT1A, axonal damage may not occur unless the nerves are subjected to compression. PMP22 duplication in Schwann cells results in disturbance of axonal cytoskeletal organisation, resulting in distal axonal degeneration and fibre loss. ${ }^{13}$ However, the effect of PMP22 deletion on the axonal cytoskeleton is less severe. ${ }^{13}$ PMP22 deletion in itself may not cause progressive axonal involvement associated with aging, though compression induced demyelination may elicit secondary axonal loss because of deficient Schwann cell signalling to the axonal cytoskeleton. ${ }^{37}$

SNAP of the median, ulnar, and sural nerves showed marked reduction even in nerves relatively free from compression and tended to decrease with increasing age at examination. Unlike findings for CMAP, however, rates of reduction with aging did not differ significantly from those in normal controls. Sensory axons may be less susceptible than motor nerves to changes caused by entrapment.

Reduction in CMAP and SNAP may be at least partly attributed to dispersion with phase cancellation as a result of demyelinating change, as suggested by significant prolongation of waveform duration..$^{27}$ Sural nerve biopsy specimens showed a reduction in large myelinated fibre density irrespective of age, which may indicate a developmental abnormality of axons or a loss of axons relatively early in life. This axonal loss also may contribute to reduction in amplitudes. At any rate, reduction in myelinated fibres of sensory nerves in HNPP patients did not appear to be associated with acquired damage at the entrapment sites. Thus, the electrophysiological features of HNPP are a mixture of abnormalities occurring from an early stage in life and acquired features caused by repetitive insults at entrapment sites. One therapeutic strategy in HNPP patients may be directed toward prevention of axonal damage associated with entrapment.

\section{Authors' affiliations}

H Koike, M Hirayama, M Yamamoto, H Ito, N Hattori, G Sobue, Department of Neurology, Nagoya University Graduate School of Medicine, Nagoya, Japan

F Umehara, K Arimura, Department of Neurology and Geriatrics, Kagoshima University Graduate School of Medicine and Dental Sciences, Kagoshima, Japan

S Ikeda, Third Department of Medicine, Shinshu University School of Medicine, Matsumoto, Japan

Y Ando, Department of Laboratory Medicine, Kumamoto University School of Medicine, Kumamoto, Japan

M Nakazato, Third Department of Internal Medicine, Miyazaki Medical College, Miyazaki, Japan

R Kaii, Department of Clinical Neuroscience, University of Tokushima, Tokushima, Japan

K Hayasaka, Department of Pediatrics, Yamagata University School of Medicine, Yamagata, Japan

M Nakagawa, Department of Neurology, Kyoto Prefectural University of Medicine, Kyoto, Japan

S Sakoda, Department of Neurology, Osaka University Graduate

School of Medicine, Suita, Japan

K Matsumura, Department of Neurology, Teikyo University School of Medicine, Tokyo, Japan

O Onodera, Department of Neurology, Niigata University School of Medicine, Niigata, Japan

M Baba, Department of Neurology, Hirosaki University School of Medicine, Hirosaki, Japan

H Yasuda, Department of Medicine, Shiga University of Medical Science, Otsu, Japan

T Saito, Department of Rehabilitation, Kitasato University School of Allied Health Sciences, Sagamihara, Japan

J Kira, Department of Neurology, Kyushu University Graduate School of Medicine, Fukuoka, Japan

K Nakashima, Department of Neurology, Tottori University School of Medicine, Yonago, Japan

N Oka, Department of Rehabilitation, National Minami-Kyoto Hospital, Joyo, Japan

This work was supported by grants from the Ministry of Health, Labor, and Welfare of Japan.

Competing interests: none declared

\section{REFERENCES}

1 Davies DM. Recurrent peripheral nerve palsies in a family. Lancet 1954;267:266-8

2 Earl CJ, Fullerton PM, Wakefield GS, et al. Hereditary neuropathy with liability to pressure palsies: a clinical and electrophysiological study of four families. Q J Med 1964;33:481-98.

3 Behse F, Buchthal F, Carlsen F, et al. Hereditary neuropathy with liability to pressure palsies. Electrophysiological and histopathological aspects. Brain 1972;95:777-94.

4 Madrid R, Bradley WG. The pathology of neuropathies with focal thickening of the myelin sheath (tomaculous neuropathy): studies on the formation of the abnormal myelin sheath. J Neurol Sci 1975;25:415-48.

5 Oda K, Miura H, Shibasaki H, et al. Hereditary pressure-sensitive neuropathy: demonstration of "tomacula" in motor nerve fibers. J Neurol Sci 1990;98:139-48.

6 Sander S, Ouvrier RA, McLeod JG, et al. Clinical syndromes associated with tomacula or myelin swellings in sural nerve biopsies. J Neurol Neurosurg Psychiatry 2000;68:483-8

7 Chance PF, Alderson MK, Leppig KA, et al. DNA deletion associated with hereditary neuropathy with liability to pressure palsies. Cell 1993;72:143-51.

8 Mariman EC, Gabreéls-Festen AA, van Beersum SE, et al. Prevalence of the $1.5-\mathrm{Mb} 17 \mathrm{p}$ deletion in families with hereditary neuropathy with liability to pressure palsies. Ann Neurol 1994;36:650-5.

9 Tyson J, Malcolm S, Thomas PK, et al. Deletion of chromosome 17p11.2 in multifocal neuropathies. Ann Neurol 1996;39:180-6.

10 Lupski JR, de Oca-Luna RM, Slaugenhaupt S, et al. DNA duplication associated with Charcot-Marie-Tooth disease type 1A. Cell 1991;66:219-32.

11 Sancho S, Young P, Suter U. Regulation of Schwann cell proliferation and apotosis in PMP-deficient mice and mouse models of Charcot-Marie-Tooth disease type 1A. Brain 2001;124:2177-87.

12 Dyck PJ, Karnes JL, Lambert EH. Longitudinal study of neuropathic deficits and nerve conduction abnormalities in hereditary motor and sensory neuropathy type 1. Neurology 1989;39:1302-8.

13 Sahenk Z, Chen L, Mendell JR. Effects of PMP22 duplication and deletions on the axonal cytoskeleton. Ann Neurol 1999;45:16-24. 
14 Krajewski KM, Lewis RA, Fuerst DR, et al. Neurological dysfunction and axonal degeneration in Charcot-Marie-Tooth disease type 1A. Brain 2000;123:1516-27

15 Hattori N, Yamamoto M, Yoshihara T, et al. Demyelinating and axonal features of Charcot-Marie-Tooth disease with mutations of myelin-related proteins (PMP22, MPZ and Cx32): a clinicopathological study of 205 Japanese patients. Brain 2003;126:134-51.

16 Gouider R, LeGuern E, Gugenheim M, et al. Clinical, electrophysiologic, and molecular correlations in 13 families with hereditary neuropathy with liability to pressure palsies and a chromosome 17p11.2 deletion. Neurology 1995;45:2018-23

17 Pareyson D, Scaioli V, Taroni F, et al. Phenotypic heterogeneity in hereditary neuropathy with liability to pressure palsies associated with chromosome 17p1 1.2-12 deletion. Neurology 1996:46:1133-7.

18 Mouton P, Tardieu S, Govider R, et al. Spectrum of clinical and electrophysiologic features in HNPP patients with the $17 p 11.2$ deletion. Neurology 1999;52:1440-6.

19 Andersson P-B, Yuen E, Parko K, et al. Electrodiagnostic features of hereditary neuropathy with liability to pressure palsies. Neurology 2000:54:40-4.

20 Li J, Krajewski K, Shy ME, et al. Hereditary neuropathy with liability to pressure palsy: the electrophysiology fits the name. Neurology 2002;58:1769-73.

21 Koike H, Misu K, Ikeda S, et al. Type I (transthyretin Met30) familial amyloid polyneuropathy in Japan: early- vs late-onset form. Arch Neurol 2002;59:1771-6.

22 Yamamoto M, Yasuda T, Hayasaka K, et al. Locations of crossover breakpoints within the CMT1A-REP repeat in Japanese patients with CMTIA and HNPP. Hum Genet 1997:99:151-4.

23 Kiyosawa H, Lensch MW, Chance PF. Analysis of the CMTIA-REP repeat: mapping crossover breakpoints in CMT1A and HNPP. Hum Mol Genet 1995;4:2327-34.

24 Yamamoto M, Keller MP, Yasuda T, et al. Clustering of CMT1A duplication breakpoints in a 700 bp interval of the CMT1A-REP repeat. Hum Mutat 1998:11:109-13

25 Kimura J. Principles and variations of nerve conduction studies. In: Kimura J, ed. Electrodiagnosis in disease of nerve and muscle: principles and practice 3rd ed. New York: Oxford University Press, 2001:91-129.
26 Kimura J. Assessment of individual nerves. In: Kimura J, ed. Electrodiagnosis in disease of nerve and muscle: principles and practice, 3rd ed. New York: Oxford University Press, 2001:130-77.

27 Kimura J, Machida M, Ishida T, et al. Relation between size of compound sensory or muscle action potentials, and length of nerve segment. Neurology 1986;36:647-52.

28 Gilliatt RW, Melville ID, Velate AS, et al. A study of normal nerve action potentials using an averaging technique (barrier grid storage tube). I Neurol Neurosurg Psychiatry 1965;28:191-200.

29 Kimura J. The carpal tunnel syndrome: localization of conduction abnormalities within the distal segment of the median nerve. Brain 1979;102:619-35.

30 Sobue G, Yasuda T, Mitsuma T, et al. Expression of nerve growth factor receptor in human peripheral neuropathies. Ann Neurol 1988;24:64-72.

31 Misu K, Hattori N, Nagamatsu M, et al. Late-onset familial amyloid polyneuropathy type I (transthyretin Met 30-associated familial amyloid polyneuropathy) unrelated to endemic focus in Japan: clinicopathological and genetic features. Brain 1999;122:1951-62.

32 Sobue G, Hashizume Y, Mukai E, et al. X-linked recessive bulbospinal neuronopathy, a clinicopathological study. Brain 1989;112:209-32.

33 Hattori N, Ichimura M, Nagamatsu M, et al. Clinicopathological features of Churg-Strauss syndrome-associated neuropathy. Brain 1999;122:427-39.

34 Koike $\mathbf{H}$, lijima $M$, Sugiura $M$, et al. Alcoholic neuropathy is clinicopathologically distinct from thiamine-deficiency neuropathy. Ann Neurol 2003;54:19-29.

35 Dyck PJ, Giannini C, Lais A. Pathologic alterations of nerves. In: Dyck PJ, Thomas PK, Griffin JW, et al, eds. Peripheral neuropathy, 3rd ed. Philadelphia, PA: WB Saunders, 1993:514-95.

36 Korn-Lubetzki I, Argov Z, Raas-Rothschild A, et al. Family with inflammatory demyelinating polyneuropathy and the HNPP $17 \mathrm{p} 12$ deletion. Am J Med Genet 2002;1 13:275-8

37 de Waegh SM, Lee VM, Brady ST. Local modulation of neurofilament phosphorylation, axonal caliber, and slow axonal transport by myelinating Schwann cells. Cell 1992;68:451-63.

38 Rhee E, England J, Summer AJ. A computer simulation of conduction block: effects produced by actual block versus interphase cancellation. Ann Neurol 1990;28:146-56 